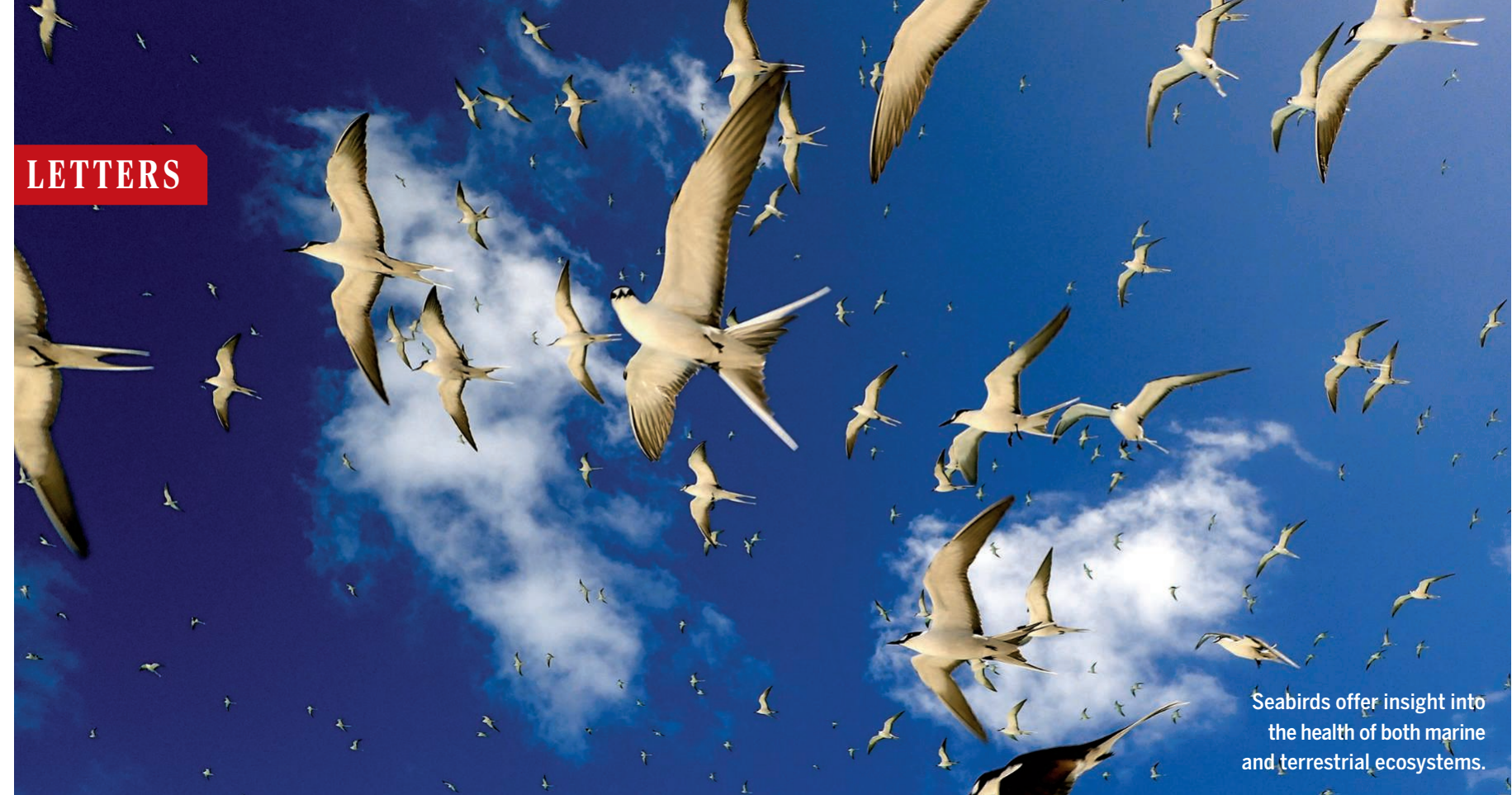

Edited by Jennifer Sills

\section{Seabirds: Sentinels beyond the oceans}

In their Perspective "Seabird clues to ecosystem health" (12 July, p. 116), E. Velarde et al. rightly point out that seabirds provide crucial information about the state of marine ecosystems. However, they do not mention the role of seabirds on land and shorelines. Seabirds that forage at sea and breed on land play an essential role in cross-ecosystem transport of energy and nutrients, shaping terrestrial (1) as well as marine (2) ecosystems. Seabird colonies can provide insight into coastal and island environments worldwide (3).

In terrestrial (4) and adjacent reef ecosystems, nutrients from seabird guano (such as nitrogen and phosphorus) have been shown to enhance productivity, growth rate, and functioning of coral reef communities (5-9). In addition, because seabirds are highly sensitive to invasive species, visitor disturbance, noise, and light (3), they rely on the tranquility and seclusion of breeding sites to reproduce. Their distribution and the demography are therefore valuable and integrative proxies of anthropogenic pressures at shore $(10,11)$. In an era of profound and worrying changes that affect both marine and terrestrial environments, seabird populations are barometers of the health of a large variety of oceanic, coastal, and insular ecosystems. Up to $47 \%$ of all seabird species are currently declining, with $37 \%$ already threatened (12), which will undoubtedly reduce the monitoring opportunities offered by these sentinel organisms.

M. Thibault ${ }^{1 *}$, F. Houlbrèque $^{1}, A$. Lorrain ${ }^{2}, E_{\text {. Vidal }}{ }^{1}$ ${ }^{1}$ Laboratoire d'Excellence Labex-CORAIL, Institut de Recherche pour le Développement (IRD), UMR ENTROPIE (IRD-Université de La Réunion-CNRS), BP A5, Nouméa Cedex 98848, New Caledonia, France. ${ }^{2}$ University of Brest, CNRS, IRD, Ifremer,

LEMAR, F-29280 Plouzane, France.

*Corresponding author.

Email: martin.thibault@ird.fr

\section{REFERENCES AND NOTES}

1. D. A. Croll, J. L. Maron, J. A. Estes, E. M. Danner, G. V. Byrd, Science. 307.1959(2005).

2. O. Shatova, S. R. Wing, M. Gault-Ringold, L. Wing, L. J. Hoffmann, J. Exp. Mar. Biol. Ecol. 483, 74 (2016).

3. M. P. Dias et al., Biol. Conserv. 237,525 (2019).

4. S. Caut, PLOS One 7, e39125 (2012).

5. A. Lorrain et al.,Sci. Rep. 7,3721 (2017)

6. N. A. Graham etal., Nature 559,250 (2018).

7. K. Gagnon, E. Rothäusler, A. Syrjänen, M. Yli-Renko, V. Jormalainen, PLOS One 8, e61284 (2013).

8. C. E. Benkwitt, S. K. Wilson, N. A. Graham, Glob. Change Biol. 25, 2619 (2019).

9. C. Savage, Sci. Rep. 9,4284(2019)

10. E. Vidal, M. Thibault, K. Bourgeois, Nature 560 167 (2018).

11. United Nations, The First Global Integrated Marine Assessment: World Ocean Assessment I (Cambridge University Press, Cambridge, UK, 2017).

12. Birdl ife International, State of the World's Birds: Taking the Pulse of the Planet (BirdLife International, Cambridge, UK, 2018).

10.1126/science.aaz7665

\section{Save horseshoe crabs and coastal ecosystems}

The Chinese horseshoe crab (Tachypleus tridentatus) is one of the oldest marine living fossils. Horseshoe crabs have existed for more than 445 million years (1), but populations of the Chinese species have plummeted in recent decades as a result of increasing biomedical demands, harvesting for human consumption, and habitat loss (2). Urgent action is needed to reverse population declines and protect coastal ecosystems.

Chinese horseshoe crabs play key roles in coastal ecosystems as benthic predators, prey, bioturbators, and hosts for epibionts (3). Their eggs are a major protein source for migratory shorebirds (4). However, discovery and commercialization of the Limulus amoebocyte lysate (LAL) test for bacterial endotoxin, which uses blood from horseshoe crabs, has driven population declines (5). More than 610,000 horseshoe crabs were harvested and nearly 80,000 killed for LAL production in 2012 alone (6). Adult horseshoe crabs are also a prized dish in many seafood restaurants. A survey in south China found that 132 of 155 restaurants offered horseshoe crabs (7). Climate change and associated ocean acidification, urbanization, land reclamation, and water pollution are exacerbating habitat loss, affecting horseshoe crabs' spawning activities and juvenile nurseries (8). Breeding pairs in Guangxi Province, the species' Chinese stronghold, declined from between 600,000 and 700,000 in the 1990s to 40,000 20 years later (9). Declining horseshoe crab populations have implications for entire coastal ecosystems, especially shorebirds (4).

In March 2019, the International Union for Conservation of Nature (IUCN) listed the species as endangered (10). Urgent measures are needed to save horseshoe crabs. Research into animal-free LAL production is a priority (6). Management action should focus on protecting spawning and nursery habitats. Relatively few Chinese people are aware of the horseshoe crabs' plight. Public education is therefore needed, especially 